\title{
DEVELOPMENT AND VALIDATION OF RP-HPLC METHOD FOR THE ESTIMATION OF DOLUTEGRAVIR AND RILPIVIRINE IN BULK AND PHARMACEUTICAL DOSAGE FORM AND ITS APPLICATION TO RAT PLASMA
}

\author{
VEERASWAMI B*, NAVEEN VMK \\ Department of Chemistry, GITAM Deemed to be University, Visakhapatnam, India. Email: naveenvmk85@gmail.com \\ Received: 10 September 2018, Revised and Accepted: 10 October 2018
}

\begin{abstract}
Objective: The present paper describes a simple, accurate, and precise reversed-phase high-performance liquid chromatography (HPLC) method for rapid and simultaneous quantification of dolutegravir (DTG) and rilpivirine (RPV) in bulk and pharmaceutical dosage form and rat plasma.

Methods: The chromatographic separation was achieved on Phenomenex C18 (150x4.6mm, $5 \mu \mathrm{m})$. Mobile phase contained a mixture of $0.1 \%$ Ortho phosphoric acid and acetonitrile in the rato of $60: 40 \mathrm{v} / \mathrm{v}$, flow rate $1.0 \mathrm{ml} / \mathrm{min}$ and ultraviolet detection at $262 \mathrm{~nm}$.

Results: The retention time of DTG and RPV was $4.35 \mathrm{~min}$ and $7.73 \mathrm{~min}$, respectively. The proposed method shows a good linearity in the concentration range of $10-150 \mu \mathrm{g} / \mathrm{ml}$ for DTG and $5-75 \mu \mathrm{g} / \mathrm{ml}$ for RPV under optimized conditions. Precision and recovery study results are in between 98 and $102 \%$. In the entire robustness conditions, percentage relative standard deviation is $<2.0 \%$. Degradation has minimum effect in stress condition and solutions are stable up to $24 \mathrm{~h}$. DTG and RPV drugs are release $98 \%$ at $2 \mathrm{~h}$ in rat body.

Conclusion: This method is validated for different analytical performance parameters like linearity. Precision, accuracy, limit of detection, limit of quantification, robustness, and pharmacokinetic study were determined according to the International Conference of Harmonization (ICH) Q2B guidelines. All the parameters of validation were found in the acceptance range of ICH guidelines. The same method is also applied for plasma samples study in bioanalytical work.
\end{abstract}

Keywords: Reversed-phase high-performance liquid chromatography, Dolutegravir, Rilpivirine and rat plasma.

(C) 2019 The Authors. Published by Innovare Academic Sciences Pvt Ltd. This is an open access article under the CC BY license (http://creativecommons. org/licenses/by/4. 0/) DOI: http://dx.doi.org/10.22159/ajpcr.2019.v12i2.29669

\section{INTRODUCTION}

Dolutegravir (DTG) marketed name as Tivicay is an antiretroviral medication [1] used together with other medication to treat human immunodeficiency virus (HIV)-acquired immune deficiency syndrome [2]. It may also be used, as part of post-exposure prophylaxis [3] to prevent HIV infection following potential exposure [4]. It is taken by mouth. DTG is an HIV integrase strand transfer inhibitor [5] which blocks the functioning of HIC integrase [6] which is needed for viral replication.

RLP is a pharmaceutical drug [7-9] developed by Tibotec for the treatment of HIV infection [10]. It is the second-generation nonnucleoside reverse transcriptase inhibitor (NNRTI) with higher potency, longer half-life [11], and reduced side effect profile [12] compared with older NNRTIs such as efavirenz $[13,14]$.

The literature survey revealed that there are only two methods reported high-performance liquid chromatography (HPLC) $[15,16]$ and in ultraviolet (UV) spectrophotometric methods [17] two reports for only DTG $[18,19]$. There are no common methods for both quantitative analysis and bioanalytical [20] method.

The objective of the present work was the development and validation of a method for the estimation of DTG and rilpivirine (RPV).

\section{METHODS}

\section{Instrumentation}

The analysis was performed on Water Alliance-e2695 chromatographic system equipped with a quaternary pump and photodiode array detector-2996. Chromatographic software Empower-2.0 was used for data collection.

\section{Chemicals and reagents}

Acetonitrile (HPLC grade), orthophosphoric acid (HPLC grade), and water (HPLC grade) were purchased from Merck (India) Ltd., Worli, Mumbai, India. DTG and RPV reference standards were produced from Glenmark Pharmaceuticals Limited, Mahape, Navi Mumbai, India.

\section{Chromatographic conditions}

Chromatographic analysis was done using isocratic elution, mobile phase in the ratio of acetonitrile: buffer $(0.1 \%$ o-phthaldialdehyde) $(60: 40 \mathrm{v} / \mathrm{v})$ was filtered through $0.45 \mu$ membrane filter paper. The flow rate of the mobile phase was monitored at $1.0 \mathrm{ml} / \mathrm{min}$ and eluents were detected at $262 \mathrm{~nm}$. By injecting the volume $10 \mu \mathrm{l}$ with a run time $10 \mathrm{~min}$.

\section{Selection of wavelength}

Using photodiode spectrophotometer, the absorption spectra of the solution of two drugs are scanned in the UV region $200-400 \mathrm{~nm}$ spectra are shown in Fig. 1. The spectra of the DTG and RPV show at different $\lambda$ max, namely $258.3 \mathrm{~nm}$ and $265.4 \mathrm{~nm}$, respectively. By average, the two wavelengths at $262 \mathrm{~nm}$ were selected as detection wavelength for HPLC chromatographic method.

\section{Preparation of standard solution}

$100 \mathrm{mg}$ of DTG and $50 \mathrm{mg}$ of RPV working standards were weighed accurately and transferred into a $100 \mathrm{ml}$ volumetric flask. Added $70 \mathrm{ml}$ of mobile phase sonicated for $20 \mathrm{~min}$ to dissolve the components makeup to the mark with diluent and mixed. After that, $5 \mathrm{ml}$ of above solution diluted to $50 \mathrm{ml}$ with mobile phase. 


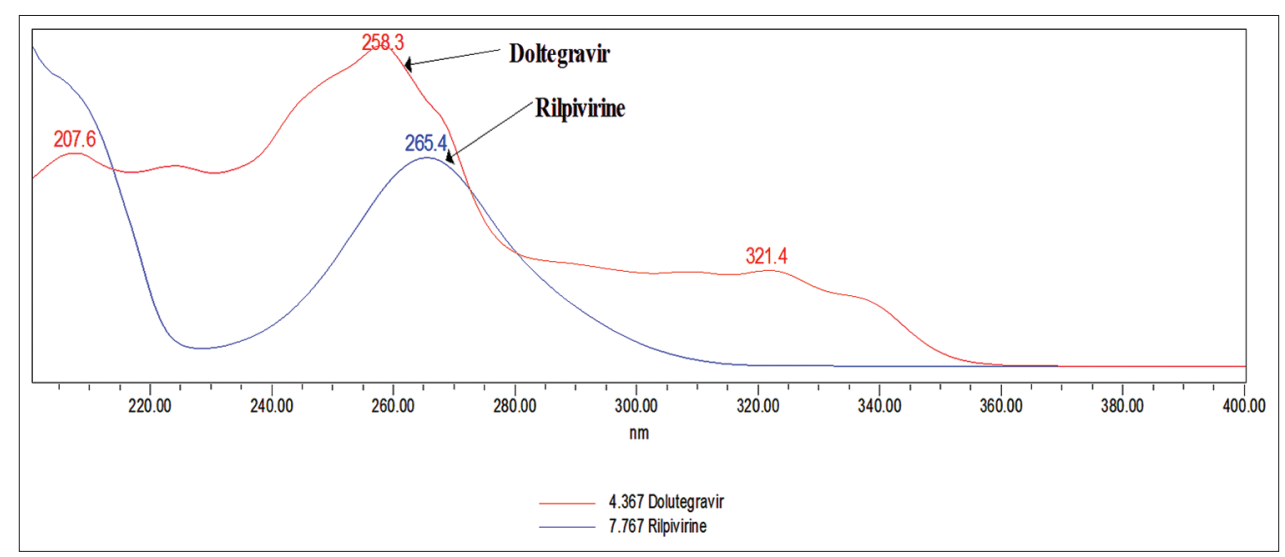

Fig. 1: Photodiode array spectrum for dolutegravir and rilpivirine

\section{Preparation of sample solution}

Weighed 20 tablets and take the one tablet equivalent weight. Crush the 20 tablets into powder form take 10 tablets equivalent weight of sample into a $100 \mathrm{ml}$ volumetric flask added $70 \mathrm{ml}$ of diluent sonicated for $30 \mathrm{~min}$ after that makeup to the volume with diluent. Further diluted 5-50 ml with mobile phase and filtered through $0.45 \mu$ nylon syringe filter.

\section{Preparation of rat plasma sample preparation}

The liquid-liquid extraction method was used to isolate DTG and RPV in rat plasma. For this, $100 \mu \mathrm{l}$ of plasma sample (respective concentration) were added into labeled polypropylene tubes and vortexed briefly after that $2.5 \mathrm{ml}$ of acetonitrile was added and vortexed for approximately $10 \mathrm{~min}$ followed by centrifuging at $4000 \mathrm{rpm}$ at $20^{\circ} \mathrm{C}$. Supernatant from each sample was transferred to labeled through tube and evaporated at $40^{\circ} \mathrm{C}$ until dryness. These samples were reconstituted with $500 \mu \mathrm{l}$ of acetonitrile and vortexed briefly and then transferred the sample into autosampler vials for injection.

\section{Validation}

\section{System suitability}

As per the test method, the standard solutions were prepared and injected into HPLC system from which the evaluated system suitability parameters are found to be within the limit.

\section{Specificity}

The specificity defined as the ability of the method to measure the analyte accurately and specifically in the presence of components present in the sample matrix was determined by analysis of chromatograms of drugfree and drug-added placebo formulation.

\section{Linearity}

The ability of the method to produce results those are directly or indirectly proportional to the concentration of the analyte in samples within a given range.

\section{Precision}

The degree of closeness of the agreement among individual test results when the method is applied to multiple samplings of a homogeneous sample. It is a measure of either the degree of reproducibility (agreement under different conditions) or repeatability (agreement under the same conditions) of the method.

\section{Accuracy}

The closeness of results was obtained by a method to the true value. It is a measure of the exactness of the method.

\section{Limit of detection and quantification}

The detection of limit and quantification limit for each analyte were determined based on a signal-to-noise concept, as the lowest concentration at which signal-to-noise ratio between 3 or 2:1 and $10: 1$, respectively, with defined precision and accuracy under the given experimental conditions.

\section{Stability}

Standard and sample solutions were subjected to $24 \mathrm{~h}$ stability at RT and $2-8^{\circ} \mathrm{C}$. The stability of these solutions was studied and observed for changes in the area and retention time of the peaks which were then compared with the pattern of the chromatogram of the freshly prepared solution.

\section{Robustness}

Robustness of the method was studied by slightly changes in experimental conditions such as flow rate and organic composition. This was performed by same analyst with same instrument.

\section{Ruggedness}

Ruggedness of the method was studied using different source of analysts, instruments, wavelengths, and columns with same experimental conditions.

\section{RESULTS AND DISCUSSION}

\section{Method validation}

Inthismethod,systemsuitability,linearity, precision, accuracy, robustness, limitof detection (LOD), limit of quantification (LOQ), forced degradation, and stability are validated for the selected DTG and RPV drugs.

\section{System suitability}

$100 \mu \mathrm{g} / \mathrm{ml}$ of DTG and $50 \mu \mathrm{g} / \mathrm{ml}$ of RPV was prepared and injected into the HPLC system. Resolution of the DTG was 13.21 from the RPV. The number of theoretical plate counts for DTG and RPV was 6261 and 11,234 respectively. Tailing factor for DTG and RPV was 1.06 and 1.14, respectively (Fig 2).

\section{Linearity}

Linearity of the method was evaluated by preparing a standard solution containing $100 \mu \mathrm{g} / \mathrm{ml}$ of DTG and $50 \mu \mathrm{g} / \mathrm{ml}$ of RPV $(100 \%$ of targeted level of the assay concentration). Sequential dilutions were performed to give solutions at $10,25,50,100$, and $150 \%$ of the target concentrations. These were injected and peak areas used to plot calibration curves against the concentration. The correlation coefficient values of these three analytes were 0.999 . The results are shown in Table 1 and Figs. 3 and 4.

\section{Limit of detection and quantification}

Limit of detection and quantification minimum concentration level at which the analyte can be reliably detected, quantified using the standard formulas (3.3 times $\sigma / \mathrm{s}$ for LOD and LOQ respectively). LOD values for DTG and RPV were $0.01 \mu \mathrm{g} / \mathrm{ml}$ and $0.005 \mu \mathrm{g} / \mathrm{ml}$ 


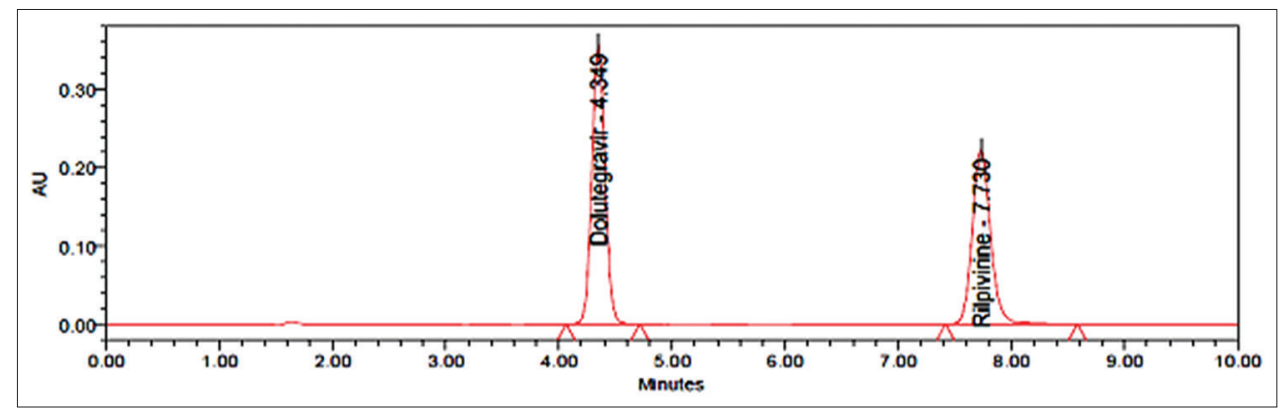

Fig. 2: Chromatogram for standard solution

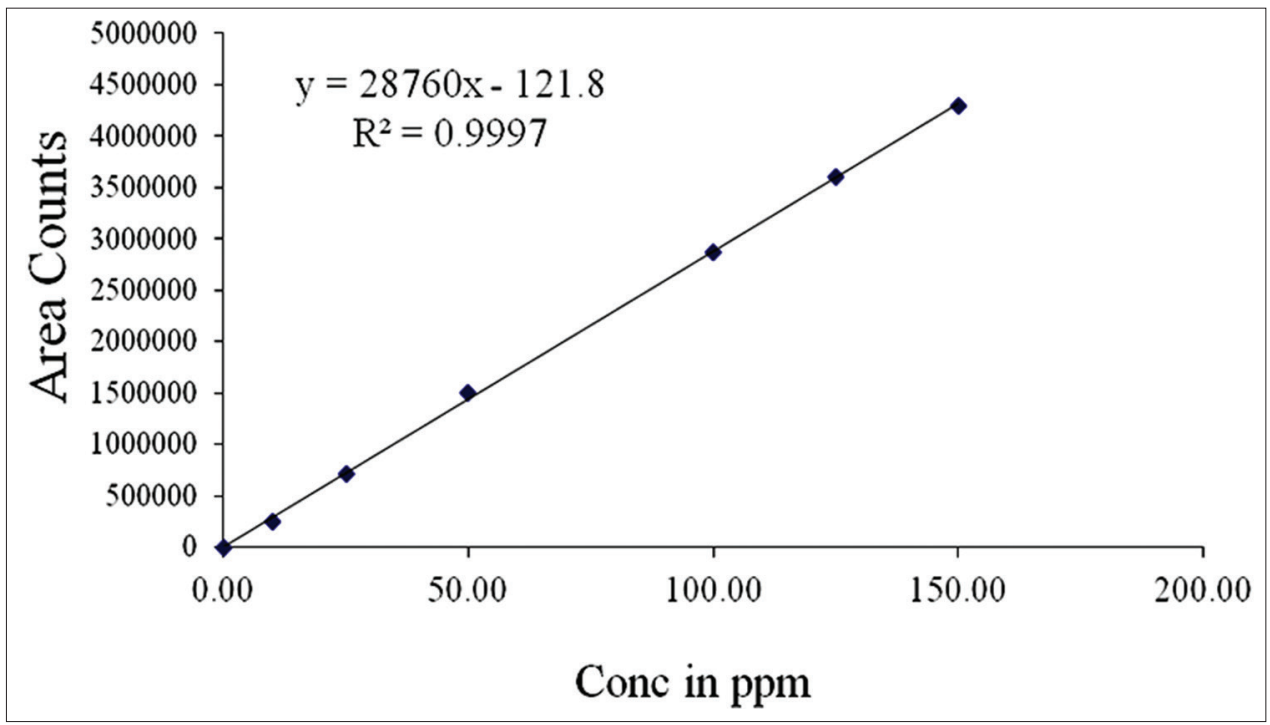

Fig. 3: Linearity plot for dolutegravir

their $\mathrm{s} / \mathrm{n}$ values are 3 and 4 , respectively. LOQ values for DTG and $\mathrm{RPV}$ were $0.1 \mu \mathrm{g} / \mathrm{ml}$ and $0.05 \mu \mathrm{g} / \mathrm{ml}$ their $\mathrm{s} / \mathrm{n}$ values are 23 and 26 , respectively.

\section{Precision}

Method precision was investigated by the analysis of six separately prepared samples of the same batch. From this, six separate sample solutions were injected to obtain their areas. The calculate mean and percentage relative standard deviation (RSD) values. The present method was found to be precise as percentage RSD of $<2 \%$, and also, the percentage assay values were close to being $100 \%$. The results are given in Table 2.

\section{Accuracy}

Accuracy was determined by recovery studies which were carried out in three different concentrations levels $(50,100$, and 150\%). APIs with concentration of 50,100 , and $150 \mu \mathrm{g} / \mathrm{ml}$ of DTG; 25, 50, and $75 \mu \mathrm{g} / \mathrm{ml}$ of RPV were prepared. As per the test method, the test solution was injected three preparations each spike level and the assay was performed. The percentage recovery values were found to be in the range of $100.22-100.45 \%$ for DTG and $100.37-100.58 \%$ for RPV. RSD values were found to be $<2 \%$. The results are given in Table 3.

\section{Ruggedness}

Ruggedness of the method was studied and showed that chromatographic patterns did not significantly change when different HPLC system, analyst, and column. The value of percentage of RSD was $<2 \%$ and exhibits the ruggedness of the developed method.
Table 1: Results for linearity

\begin{tabular}{llll}
\hline Analytes & Linearity range & $\begin{array}{l}\text { Equation of } \\
\text { calibration curve }\end{array}$ & $\begin{array}{l}\text { Correlation } \\
\text { coefficient }\end{array}$ \\
\hline DTG & $10.0-150.0 \mu \mathrm{g} / \mathrm{ml}$ & $\mathrm{Y}=28760 \mathrm{x}+121.8$ & 0.999 \\
RPV & $5.0-75.0 \mu \mathrm{g} / \mathrm{ml}$ & $\mathrm{Y}=10064 \mathrm{x}+10930$ & 0.999 \\
\hline
\end{tabular}

DTG: Dolutegravir, RPV: Rilpivirine

Table 2: Results for method precision

\begin{tabular}{llll}
\hline Analyte & $\begin{array}{l}\text { Amount } \\
\text { present (mean) }\end{array}$ & $\begin{array}{l}\text { \% assay } \\
\text { (mean) }\end{array}$ & $\begin{array}{l}\text { \% RSD of } \\
\text { assay }\end{array}$ \\
\hline DTG & $100 \mathrm{mg}$ & 100.28 & 0.15 \\
RPV & $50 \mathrm{mg}$ & 100.14 & 0.26 \\
\hline
\end{tabular}

DTG: Dolutegravir, RPV: Rilpivirine, RSD: Relative standard deviation

Table 3: Results for accuracy

\begin{tabular}{lllll}
\hline $\begin{array}{l}\text { \% of target } \\
\text { conc. }\end{array}$ & $\begin{array}{l}\text { DTG (\% } \\
\text { recovery) }\end{array}$ & $\begin{array}{l}\text { DTG } \\
\text { (\% RSD) }\end{array}$ & $\begin{array}{l}\text { RPV (\% } \\
\text { recovery) }\end{array}$ & $\begin{array}{l}\text { RPV } \\
\text { (\% RSD) }\end{array}$ \\
\hline 50 & 100.22 & 0.24 & 100.37 & 0.58 \\
100 & 100.38 & 0.45 & 100.46 & 0.67 \\
150 & 100.45 & 1.01 & 100.58 & 0.64 \\
\hline
\end{tabular}

DTG: Dolutegravir, RPV: Rilpivirine, RSD: Relative standard deviation

\section{Robustness}

Robustness of the method found to be percentage RSD should be $<2 \%$. Slightly variations were done in the optimized method parameters such 
Table 4: Results for robustness

\begin{tabular}{|c|c|c|c|c|}
\hline $\begin{array}{l}\text { Drug } \\
\text { name }\end{array}$ & $\begin{array}{l}\text { Flow plus ( } 1.2 \mathrm{ml} / \mathrm{min}) \\
\text { (\% RSD) }\end{array}$ & $\begin{array}{l}\text { Flow minus } \\
(0.8 \mathrm{ml} / \mathrm{min})(\% \mathrm{RSD})\end{array}$ & $\begin{array}{l}\text { Org. plus }(55+45) \\
\text { (\% RSD) }\end{array}$ & $\begin{array}{l}\text { Org. minus }(65+35) \\
\text { (\% RSD) }\end{array}$ \\
\hline DTG & 0.12 & 0.51 & 0.27 & 0.87 \\
\hline RPV & 0.28 & 0.37 & 0.41 & 0.74 \\
\hline
\end{tabular}

DTG: Dolutegravir, RPV: Rilpivirine, RSD: Relative standard deviation

Table 5: Results for stability

\begin{tabular}{lllll}
\hline $\begin{array}{l}\text { Time } \\
\text { intervals }\end{array}$ & $\begin{array}{l}\text { DTG } \\
\text { (\% assay) }\end{array}$ & \% difference & $\begin{array}{l}\text { RPV } \\
\text { (\% assay) }\end{array}$ & \% difference \\
\hline Initial & 100.58 & 0.00 & 100.34 & 0.00 \\
$12 \mathrm{~h}$ & 100.36 & 0.22 & 100.27 & 0.07 \\
$18 \mathrm{~h}$ & 100.24 & 0.14 & 100.15 & 0.12 \\
$24 \mathrm{~h}$ & 100.13 & 0.11 & 100.08 & \\
\hline
\end{tabular}

DTG: Dolutegravir, RPV: Rilpivirine

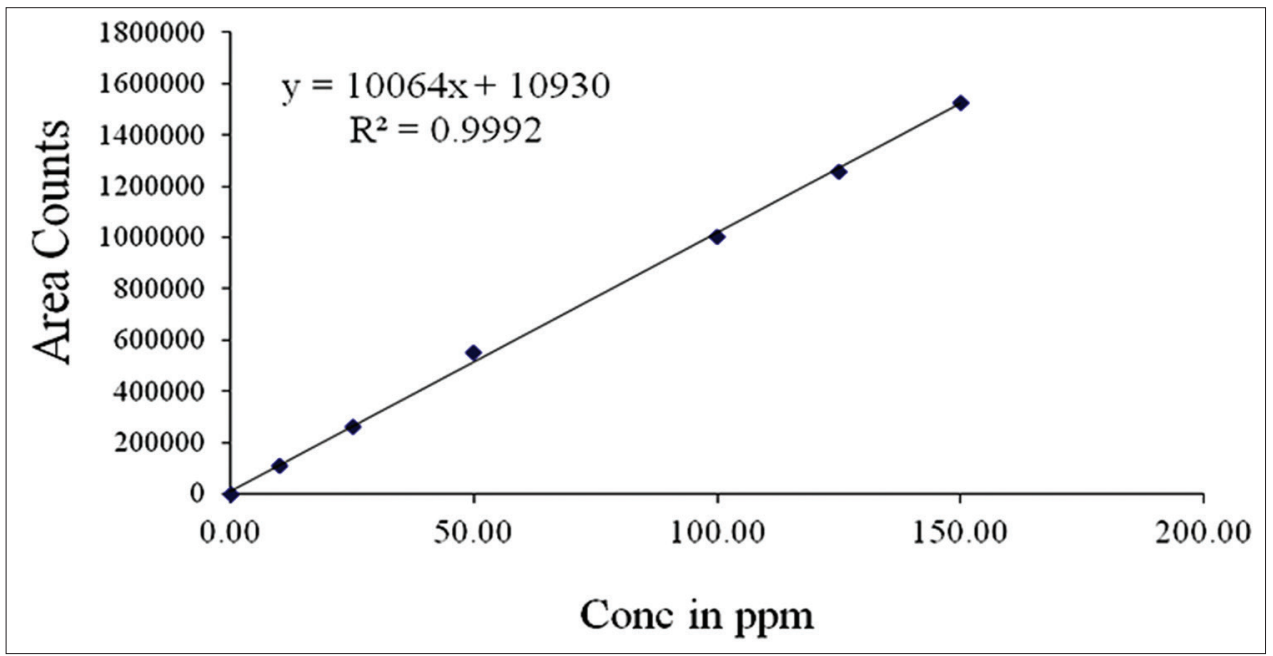

Fig. 4: Linearity plot for rilpivirine

as flow rate $( \pm 0.2 \%)$ and organic content in mobile phase $( \pm 5 \%)$. The results are given in Table 4.

\section{Stability}

Stability of standard and sample solutions is studied initial to $24 \mathrm{~h}$ in stored at room temperature and $2-8^{\circ} \mathrm{C}$. They are injected at different time intervals. The difference between initial to $24 \mathrm{~h}$ percentage assay not more than $2.0 \%$. There is no effect in storage conditions for DTG and RPV drugs. The results are shown in Table 5.

\section{Forced degradation}

Forced degradation conditions such as acidic, basic, oxidative, reduction, thermal, hydrolysis, and photolytic stresses were attempted as per the International Conference of Harmonization (ICH) guidelines Q1A (R2). There is an effect of assay results. The results are shown in Table 6.

\section{Recovery study for rat plasma}

DTG and RPV sample were injected into rat body collected samples at different time intervals such as $0,0.5,1.0,1.5,2.0$, and $2.5 \mathrm{~h}$. After that, sample is prepared as per test method injected into chromatographic system record their values. At $2 \mathrm{~h}$, the sample reaches the maximum result, suddenly down to $2.5 \mathrm{~h}$. Results are shown in Table 7. Moreover, plot is shown in Fig. 5.

\section{CONCLUSION}

This method described the quantification of DTG and RPV in bulk and pharmaceutical formulation as per the ICH guidelines. The developed

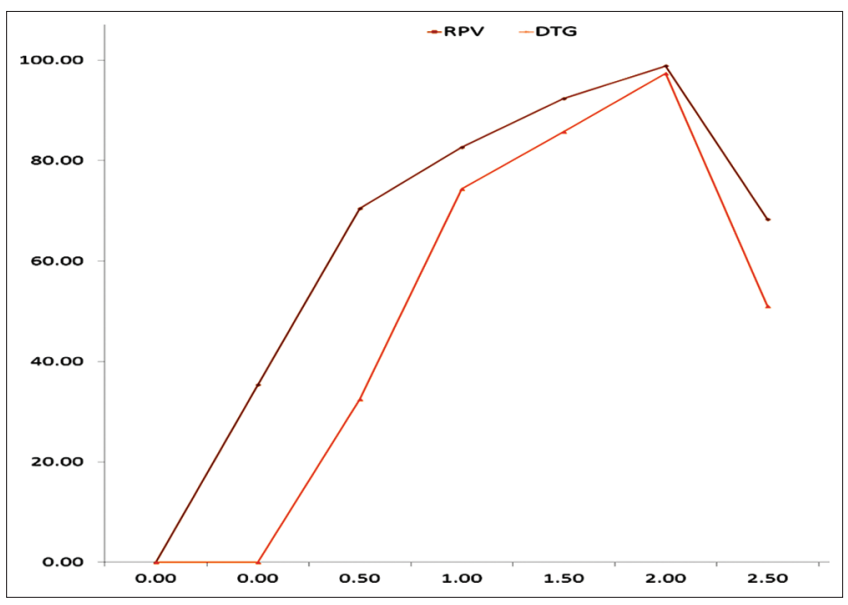

Fig. 5: Recovery plot for rat plasma

method was found to be accurate, precise, linear, and reliable. The advantage lies in the simplicity of sample preparation and the cost economic reagents were used. In addition, two compounds are eluted within 10 mins. Moreover, also, same method is used for bioanalytical plasma samples. The proposed HPLC conditions ensure sufficient resolution and the precise quantification of the compounds. Statistical analysis of the experimental result indicates that the precision and 
Table 6: Results for forced degradation

\begin{tabular}{llll}
\hline Degradation & DTG (\% assay) & \% degradation & RPV (\% assay) \\
\hline Control & 100.45 & 0.00 & 100.38 \\
Acid & 92.28 & 8.17 & 91.62 \\
Alkali & 88.37 & 12.08 & 90.87 \\
Peroxide & 91.67 & 8.78 & 92.36 \\
Reduction & 98.45 & 2.00 & 96.92 \\
Thermal & 95.78 & 4.67 & 93.28 \\
Photolytic & 99.57 & 0.88 & 98.96 \\
Hydrolysis & 97.63 & 2.82 & 98.14 \\
\hline
\end{tabular}

DTG: Dolutegravir, RPV: Rilpivirine

Table 7: Recovery study in rat plasma

\begin{tabular}{lll}
\hline Time intervals (h) & DTG $(\mathbf{n g} / \mathbf{m l})$ & RPV $(\mathbf{n g} / \mathbf{m l})$ \\
\hline 0 & 35.36 & 0.00 \\
0.5 & 70.48 & 32.48 \\
1.0 & 82.67 & 74.36 \\
1.5 & 92.38 & 85.75 \\
2.0 & 98.87 & 97.36 \\
2.5 & 68.31 & 50.97 \\
\hline
\end{tabular}

DTG: Dolutegravir, RPV: Rilpivirine

reproducibility data are satisfactory. The developed chromatographic method can be effectively applied for routine analysis in drug research.

\section{AUTHORS' CONTRIBUTION}

Veeraswami B has provided the design, intellectual content, innovations, and protocol for conducting the experiment along with mentorship. Naveen VMK has majorly performed the analysis in laboratory, literature collection, and sincerely authored the article.

\section{CONFLICTS OF INTEREST}

The authors declare that there are no conflicts of interest regarding the publication of this article.

\section{REFERENCES}

1. Moore RD, Chaisson RE. Natural history of HIV infection in the era of combination antiretroviral therapy. AIDS 1999;13:1933-42.

2. British Medical Association. British National Formulary. $69^{\text {th }}$ ed. London: BNF; 2015. p. 429.

3. Landovitz RJ, Currier JS. Postexposure prophylaxis for HIV infection. N Engl J Med 2009;361:1768-75.

4. ViiV Healthcare. Juluca (dolutegravir and rilpivirine) tablets prescribing information. The American Society of Health-System pharmacists, Research Triangle Park, NC; Nov 2017.

5. Steigbigel RT, Cooper DA, Kumar PN, Eron JE, Schechter M, Markowitz M, et al. Raltegravir with optimized background therapy for resistant HIV-1 infection. N Engl J Med 2008;359:339-54.

6. Takao M. Non-enzymatic functions of retroviral integrase: The next target for novel anti-HIV drug development. Virology 2011;2:210.

7. Drug definition US FDA Drug approval process, Phar Pharma J. Avaliable from: www.pharmacistspharmajournal.org, 2010.

8. US Federal Food, Drug and Cosmetic Act, Sec 210; 2008

9. Directive of the European Parliament and of the Council; 2004.

10. Stellbrink HJ. Antiviral drug in the treatment of AIDS. Eur J Med Res 2007; 12:483-95.

11. Lin VW, Cardenas DD. Spinal Cord Medicine. New York: Demos Medical Publishing, LLC; 2003. p. 251.

12. International Conference on Harmonisation of Technical Requirements For Registration of Pharmaceuticals For Human Use. Guideline for Good Clinical Practice 2014. p. 2.

13. Goebel F, Yakovlev A, Pozniak AL, Vinogradova E, Boogaerts G, Hoetelmans R, et al. Short-term antiviral activity of TMC278-a novel NNRTI-in treatment-naive HIV-1-infected subjects. AIDS 2006;20:1721-6.

14. Poznaik A, Ramirez M, Mohap L. 48-week Primary Analysis of Trail TMC 278-C204: TMC 278 Demonstrate Potent and Sustained Efficacy in ART-Naive Patients. $14^{\text {th }}$ Conference on Retroviruses and Opportunistic Infections; 2007.

15. Joseph J, Hepsbeah NJ, Deepthi K. Analytical method development and validation for the simultaneous estimation of dolutegravir and rilpivirine using RP-HPLC method in both bulk and pharmaceutical dosage form. Eur J Biomed Pharm Sci 2016;3:237-43.

16. Damel MC, Prdeshi AN. Stability indicating HPLC method for rilpivirine and dolutegravir sodium. Eur J Biomed Pharm Sci 2017;4:454-9.

17. Cozzi V, Charbe N, Baldelli S, Castoldi S, Atzori C, Cattaneo D, et al. Development and validation of a chromatographic ultraviolet method for the simultaneous quantification of dolutegravir and rilpivirine in human plasma. Ther Drug Monit 2016;38:407-13.

18. Satyadev TN, Ch B, Sundar BS. Development and validation of high performance liquid chromatographic method for the determination of dolutegravir in human plasma. Pharm Sin 2018;6:65-72.

19. Balasaheb BG, Balasaheb AK, Subhash TR, Jijabapu K, Sudhakar PS, Development and validation of UV spectrophotometric method for estimation of dolutegravir sodium in tablet dosage form. Malaysian J Anal Sci 2015; 19:1156-63.

20. Brain PB. Welcome to bioanalysis. Bioanalysis 2009;1:1-2. 